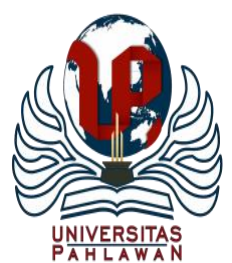

Jurnal Abdidas Volume 2 Nomor 4 Tahun 2021 Halaman 995-1002

JURNAL ABDIDAS

http://abdidas.org/index.php/abdidas

\title{
Sosialisasi Diversifikasi dan Strategi Promosi dalam Meningkatkan Penjualan Produk Anyaman Purun Desa Perdamaian
}

\author{
T. Lyza Tahura Chairunnisa ${ }^{1 凶}$, Sarah Imelda $^{2}$, Ernita Rosmika ${ }^{3}$ \\ Manajemen, Universitas Harapan Medan, Indonesia ${ }^{1,2}$ \\ Manajemen, Universitas Amir Hamzah, Indonesia ${ }^{3}$ \\ E-mail: tengkulyza@gmail.com ${ }^{1}$, sarahimelda84@gmail.com ${ }^{2}$, nitarose06@gmail.com $^{3}$
}

\begin{abstract}
Abstrak
Tujuan pelaksanaan kegiatan pengabdian masyarakat mengenai sosialisasi diversifikasi dan strategi promosi ini diharapkan dapat meningkatkan pengetahuan dan keterampilan pengrajin anyaman purun, dan juga agar dapat meningkatkan skala ekonomi, khususnya mitra para pengrajin anyaman purun di Desa Perdamaian Kwala Begumit Kecamatan Binjai Kabupaten Langkat Provinsi Sumatera Utara. Selain itu, juga diharapkan berpeluang memperoleh kerjasama dengan pemerintah setempat juga mengembangkan potensinya sehingga dapat meningkatkan taraf hidup keluarga. Tahapan dalam kegiatan pengabdian ini meliputi: tahap persiapan, pelaksanaan dan evaluasi. Melalui sosialisasi yang diberikan mitra sudah mengetahui pentingnya diversifikasi dan strategi promosi bagi produk anyaman purun yang dibuat oleh pengrajin sehingga dapat mempunyai nilai jual yang baik.
\end{abstract}

Kata kunci: diversifikasi, strategi promosi, meningkatkan penjualan

\section{Abstract :}

The purpose of implementing community service activities regarding the dissemination of diversification and promotional strategies is expected to increase the knowledge and skills of purun woven craftsmen, and also to be able to increase economic scale, especially partners for purun woven craftsmen in Peace Village Kwala Begumit, Binjai District, Langkat Regency, North Sumatra Province. In addition, it is also hoped that the opportunity to obtain cooperation with the local government is also to develop its potential so that it can improve the standard of living of the family. The stages in this service activity include: preparation, implementation and evaluation stages. Through the socialization provided, partners already know the importance of diversification and promotion strategies for purun woven products made by craftsmen so that they can have a good selling value.

Keywords : diversification, promotion strategy, increasing sales

Copyright (c) 2021 T. Lyza Tahura Chairunnisa, Sarah Imelda, Ernita Rosmika

$\triangle$ Corresponding author

Address : Universitas Harapan Medan

Email : tengkulyza@gmail.com

ISSN 2721- 9224 (Media Cetak)

DOI $\quad$ : https://doi.org/10.31004/abdidas.v2i4.399

ISSN 2721- 9216 (Media Online) 
996 Sosialisasi Diversifikasi dan Strategi Promosi dalam Meningkatkan Penjualan Produk Anyaman Purun Desa Perdamaian- T. Lyza Tahura Chairunnisa, Sarah Imelda, Ernita Rosmika

DOI: https://doi.org/10.31004/abdidas.v2i4.399

\section{PENDAHULUAN}

Paradigma baru dalam pembangunan ekonomi daerah mengharuskan perusahaan mengembangkan pekerjaan yang sesuai dengan penduduk daerah, mengembangkan lembagalembaga ekonomi baru, menciptakan keunggulan kompetitif didasarkan pada kualitas lingkungan, menggerakkan ekonomi berbasis pengetahuan dan inovasi (Kuncoro, 2014). Besarnya konsumsi rumah tangga bukanlah menjadi indikator kemajuan sebuah wilayah, namun perlu diimbangi dengan produksi dan nilai kreatifitas (industri rumah tangga). Desa Perdamaian Kwala Begumit Kecamatan Binjai Kabupaten Langkat Provinsi Sumatera Utara berbatasan dengan sebelah Utara Kecamatan Stabat, sebelah Selatan dengan Kota Binjai, sebelah Barat Kecamatan Selesai dan sebelah Timur dengan Kab Deli Serdang dan Kota Binjai. Pada umumnya, para ibu rumah tangga di Desa Perdamaian ini, dalam membantu perekonomian mengerjakan kerajinan anyaman purun berupa tikar. Tikar purun merupakan tikar khas dari Kalimantan tepatnya suku Banjar, biasanya mereka menggunakan tikar untuk menerima tamu agar bisa duduk bersila sambil bercerita dan bisa digunakan saat ada jamuan keluarga. Asal anyaman tikar purun ini adalah dari suku Banjar di Kalimantan, dengan berpindahnya suku Banjar ke Desa Perdamaian Kwala Begumit Kecamatan Binjai Kabupaten Langkat Provinsi Sumatera Utara dan mereka masih tetap melanjutkan pembuatan anyaman tikar purun ini.

(Thamrin, 2012) menyatakan purun dalam bahasa latinnya disebut Eleocharis dulcis merupakan gulma yang tumbuh subur menempati lahan rawa yang masam. Oleh karena itu, bagi petani atau masyarakat rawa, gulma ini ditanam sebagaimana layaknya padi, yang kemudian dipanen. Setelah dipanen dengan warna kehijauan, kemudian di jemur (dikeringkan) sampai warnanya coklat dan kering, kemudian digiling berulang kali sampai lunak dan kemudian di anyam untuk menjadi tikar purun. Dalam kegiatan pengabdian masyarakat ini terdapat dua mitra pengrajin anyaman purun, mitra pertama Ibu Jumaiyah sedangkan mitra kedua Ibu Siti Raudah. Kedua mitra beralamat di tempat yang sama di Desa Perdamaian Kwala Begumit Kabupaten Langkat Provinsi Sumatera Utara. Usaha ini dilakukan secara turun temurun. Pekerja masih anggota keluarga yang berjumlah dua orang. Mitra membeli satu sepeda purun yang sudah dipanen dengan harga $\mathrm{Rp} 250.000$ yang terdiri dari 12 ikatan. Satu ikatan purun dapat menghasilkan antara 2 sampai 3 anyaman tikar. Setiap satu ikat menggiling purun di kenakan biaya sebesar $\mathrm{Rp}$ 1.500 dan harga jual yang ditentukan oleh tengkulak adalah Rp 25.000 per lembar. Secara rata-rata keuntungan diperoleh mitra per satu anyaman tikar sebesar Rp 15.000 per lembar.

Permasalahan yang dihadapi oleh mitra di antaranya adalah keterbatasan keterampilan sehingga mitra belum mampu untuk membuat motif, mewarnai dan belum ada pengembangan produknya (diversifikasi), sehingga kurang menarik minat pembeli. Kerajinan anyaman purun yang dihasilkan pengrajin hanya berupa tikar saja. Padahal, kunci utama seseorang setelah memutuskan menjadi wirausaha adalah berfikir kreatif untuk menghasilkan inovasi karena 
997 Sosialisasi Diversifikasi dan Strategi Promosi dalam Meningkatkan Penjualan Produk Anyaman Purun Desa Perdamaian- T. Lyza Tahura Chairunnisa, Sarah Imelda, Ernita Rosmika

DOI: https://doi.org/10.31004/abdidas.v2i4.399

kreativitas adalah kunci sukses dalam bisnis (Hendro, 2011).

Menurut (Wijaya \& Karneli, 2017) diversifikasi merupakan suatu perluasan barang dan jasa yang dijual oleh perusahaan dengan jalan menambah produk baru atau jasa, ataupun memperbaiki tipe, warna, model, ukuran, jenis dari produk yang sudah ada dalam rangka untuk memperoleh laba maksimal.

Dengan melakukan diversifikasi maka produk yang dihasilkan mempunyai nilai tambah sehingga ketika dijual akan memperoleh keuntungan yang baik. Adapun manfaat diversifikasi (Tjiptono, 2008) yaitu: (1) perusahaan dapat mengerahkan full capacity karena tidak tergantung pada satu macam produk saja; (2) dapat memaksimumkan profitnya dengan cara mengadakan ekspansi perusahaan; (3) penemuanpenemuan baru yang menguntungkan bagi calon konsumen; (4) dengan mengadakan diversifikasi produk, perusahaan tidak bergantung pada satu pasar saja.

Masalah lainnya berkaitan dengan strategi promosi, pengrajin anyaman purun sampai saat ini hanya menjual hasil dari anyamannya kepada tengkulak saja tidak langsung menjual sendiri hasil anyamannya dengan membuka gerai di depan rumah, ke pasar tradisional yang ada di desa tersebut maupun dengan menggunakan teknologi secara online, sehingga hasil keuntungan yang didapatkan pengrajin sangatlah sedikit. Menurut (Wijaya \& Karneli, 2017) strategi promosi adalah suatu rencana permainan untuk mencapai sasaran yang diinginkan dari suatu unit bisnis. Strategi promosi merupakan siasat perusahaan dalam menjual produknya agar menarik perhatian konsumen untuk melakukan keputusan pembelian produk yang ditawarkan perusahan.

Dengan adanya program pengabdian masyarakat ini, diharapkan dapat meningkatkan pengetahuan dan keterampilan pengrajin anyaman purun berupa penyuluhan mengenai diversifikasi produk dan strategi promosi. Dan juga agar dapat meningkatkan skala ekonomi khususnya mitra para pengrajin anyaman purun di Desa Perdamaian Kwala Begumit, Kecamatan Binjai, Kabupaten Langkat, Provinsi Sumatera Utara. Selain itu, juga diharapkan berpeluang memperoleh kerjasama dengan pemerintah setempat juga mengembangkan potensinya sehingga dapat meningkatkan taraf hidup keluarga.

\section{METODE}

Sasaran dalam pengabdian masyarakat ini merupakan mitra pengrajin anyaman purun di Desa Perdamaian Kwala Begumit, Kecamatan Binjai, Kabupaten Langkat, Provinsi Sumatera Utara. Beberapa tahapan dalam pelaksanaan kegiatan pengabdian masyarakat ini adalah sebagai berikut:

1. Waktu Pelaksanaan

Kegiatan pengabdian masyarakat dilaksanakan mulai dari bulan Mei 2021. Penyuluhan dilaksanakan selama 2 hari, 8-9 Juni 2021, bertempat di kediaman pengrajin anyaman purun Desa Perdamaian Kwala Begumit, Kabupaten Langkat

2. Tahap Persiapan

Pada tahapan persiapaan meliputi kegiatan survei lokasi di Dusun I Desa Perdamaian Kwala Begumit, Kecamatan 
998 Sosialisasi Diversifikasi dan Strategi Promosi dalam Meningkatkan Penjualan Produk Anyaman Purun Desa Perdamaian- T. Lyza Tahura Chairunnisa, Sarah Imelda, Ernita Rosmika

DOI: https://doi.org/10.31004/abdidas.v2i4.399

Binjai, Kabupaten Langkat, Sumatera Utara, dan tim langsung melakukan identifikasi masalah yang dihadapi oleh mitra terkait anyaman purun yang mereka produksi. Kemudian melakukan diskusi tim pengabdian dan mitra terkait kesepakatan pelaksanaan penyuluhan pengabdian.

3. Tahap Pelaksanaan

Pada tahapan pelaksanaan Tim Pengabdian akan melaksanakan kegiatan penyuluhan mengenai diversifikasi produk dan strategi pemasaran sesuai dengan jadwal yang sudah ditentukan dan disepakati dengan mitra pengrajin anyaman purun.

4. Tahap Evaluasi

Untuk melihat keberhasilan suatu program maka perlu dilakukan evaluasi terhadap pelaksanaan program tersebut. Evaluasi diberikan dengan mengumpulkan data yang diperoleh pada saat kegiatan penyuluhan mengenai diversifikasi dan strategi promosi. Data diambil ketika diberikan penyuluhan yang disampaikan dengan metode ceramah dan tanya jawab kepada para mitra pengrajin anyaman purun.

\section{HASIL DAN PEMBAHASAN}

Pelaksanaan kegiatan pengabdian
masyarakat berupa penyuluhan mengenai
diversifikasi dan strategi promosi adalah sebagai
berikut:

1. Persiapan Pelaksanaan Pengabdian.

Kegiatan pertama yang dilakukan dalam persiapan pelaksanaan pengabdian masyarakat adalah dengan melakukan survei ke lokasi mitra dan berdiskusi dengan mitra anyaman purun untuk mengidentifikasi permasalahan yang terjadi pada mitra, menentukan waktu pelaksanaan penyuluhan pengabdian masyarakat. Mitra sangat menginginkan perubahan dari produk anyaman mereka agar mempunyai nilai jual yang layak dan produk anyaman dapat laku di pasaran, maka dari itu permasalahan yang dihadapi mitra terkait pada diversifikasi dan strategi promosi.

2. Pelaksanaan Kegiatan Pengabdian Masyarakat

Pada kegiatan penyuluhan ini disampaikan materi terkait mengenai diversifikasi dan strategi promosi yang menjadi pokok permasalahan bagi mitra.

a. Memahami Diversifikasi Produk

Anyaman merupakan seni yang mempengaruhi kehidupan dan kebudayaan masyarakat. Menganyam bermaksud proses menjaringkan atau menyilangkan bahan-bahan daripada tumbuh-tumbuhan untuk dijadikan satu rumpun yang kuat dan boleh digunakan. Bahan baku anyaman tikar purun adalah tanaman purun yang diperoleh dari PT. Langkat Nusantara Kepong Kebun Gohor Lama di Kelurahan Bingai Kecamatan Wampu Kabupaten Langkat.

Proses pembuatan anyaman purun diawali dengan proses penjemuran tanaman purun sehingga dari warna asal yang kehijauan sampai berwarna kecoklatan. Kemudian tanaman purun 
999 Sosialisasi Diversifikasi dan Strategi Promosi dalam Meningkatkan Penjualan Produk Anyaman Purun Desa Perdamaian- T. Lyza Tahura Chairunnisa, Sarah Imelda, Ernita Rosmika

DOI: https://doi.org/10.31004/abdidas.v2i4.399

digiling 4-6 kali dengan mesin penggiling secara berulang sampai tanaman purun tersebut menjadi lunak. Selanjutnya tanaman purun sudah bisa dianyam menjadi tikar. Anyaman yang dihasilkan oleh mitra hanya terbatas pada tikar dengan bentuk yang original atau polos dengan hanya ada corak garis sedikit. Maka dari itu, diperlukan motifmotif baru dalam pengembangan tikar purun. Kerajinan anyaman merupakan satu usaha atau kegiatan keterampilan masyarakat dalam pembuatan barangbarang dengan cara atau teknik susupmenyusup antara lusi dan pakan. Dalam hal ini yang disebut lusi yaitu: pita atau anyaman tegak lurus terhadap penganyam, Pita atau daun anyaman berhadapan dengan penganyam, sedangkan yang disebut pakan yaitu: pita atau daun anyaman yang disusupkan pada lusi, pita atau daun anyaman yang dilintaskan pada lusi, (Novriyanata et al., 2018).

Motif pada anyaman tikar purun ini yakni bisa motif bebas yang lebih modern dengan motif abstrak yang lebih minimalis dengan kombinasi warna yang cerah. Berikut juga dengan warna yang merupakan salah satu unsur utama dalam proses pembuatan produk agar lebih menarik dilihat. (Nurhayati, 2003) menambahkan warna adalah corak, rupa: seperti merah, putih, hijau, dan sebagainya. Warna merupakan unsur visual yang paling menonjol dari unsur yang lainnya. Kehadirannya membuat suatu benda dapat dilihat oleh mata, warna juga menunjukkan sifat dan watak yang berbeda, di samping itu warna dapat juga digunakan secara simbolik. Warna terdiri dari primer, sekunder, tersier, monokromatik warna komplementer dan warna analogus. Warna mempunyai karakteristik yang dapat mewujudkan persepsi visual yang membedakan suatu objek dengan cara mencampur warna yang satu dengan yang lainnya untuk memperoleh warna baru yang lebih artistik dan menarik. Biasanya warna untuk anyaman tikar diberikan warna yang cerah seperti merah, kuning ataupun hijau. Mitra harus berfikir kreatif dan inovatif guna menghasilkan produk anyaman yang baik dan menarik sehingga layak dijual dengan harga yang naik pula.

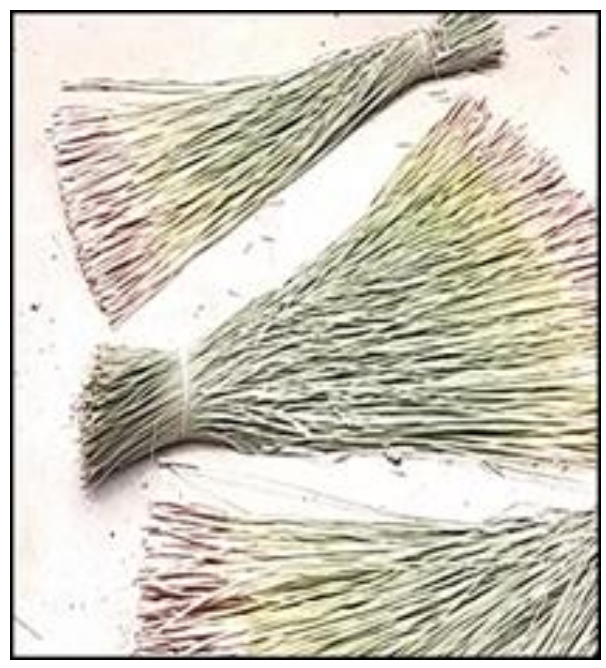

Gambar 1: Purun yang Sudah Dijemur 


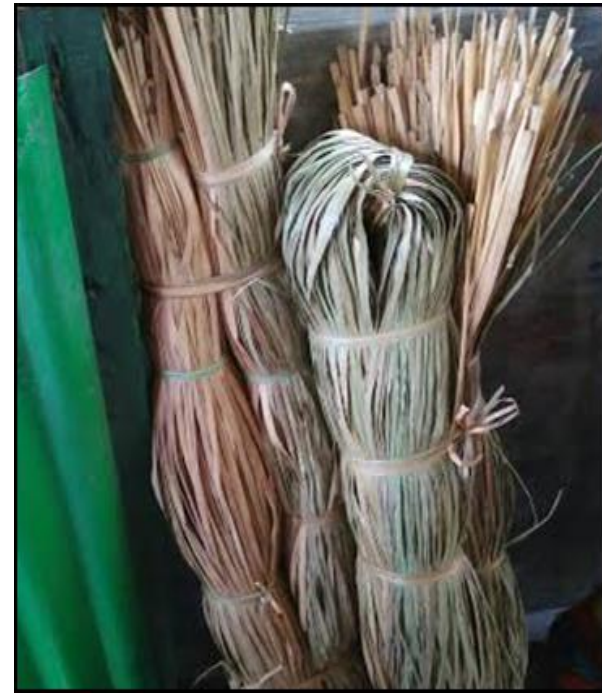

Gambar 2: Purun yang Sudah Digiling

b. Memahami Strategi Promosi

Strategi yang dilakukan setiap perusahaan berbeda-beda dilihat dari kebutuhan perusahaan itu sendiri. Walaupun strateginya berbeda tetapi tujuan dari setiap perusahaan sama yaitu untuk meningkatkan volume penjualan. Strategi promosi akan mengacu kepada komunikasi pemasaran, yang salah satunya adalah media massa. Saat ini pebisnis melakukan pemasaran melalui pemasaran online, agar produk mereka bisa dilihat dan dikenal oleh masyarakat luas dalam baik secara nasional dan bahkan internasional. Pemilik usaha Purun ini belum menggunakan strategi promosi dan hanya melakukan pemasaran dari mulut ke mulut saja, dan hanya menawarkan kepada teman dan kerabat dekat. Selama ini yang banyak membeli produk mereka adalah tengkulak saja, yang terkadang harga jual pun tengkulak yang menentukan.
Sehingga pengrajin terkadang malas berproduksi karena keuntungannya sedikit sekali. Walaupun skala usaha ini masih tergolong kecil, tetapi dengan keadaan saat ini pengrajin purun harus tetap memerlukan strategi promosi, agar bisa memberikan informasi, membujuk pembeli dengan membuat iklan yang bertujuan agar bisa menaikkan omzet penjualan.

Selama ini pengrajin belum melakukan pemasaran online, tetapi sudah ada beberapa pengrajin yang dikeluarganya sudah memiliki alat komukasi canggih yang di mana di dalamnya sudah mempunyai aplikasi jualan online. Komunikasi pemasaran modern selalu mengikuti perkembangan teknologi, memanfaatkan jaringan digital internet, diintegrasikan dan digabungkan dengan komunikasi pemasaran tradisional. Dalam hal ini pengrajin hanya mensosialisasikan tentang pemasaran online saja. Tim sangat mengharapkan sekali setelah diversifikasi berjalan dengan baik sehingga produk purun lebih berkembang lagi, maka tim pengabdian selanjutnya akan memberikan pelatihan cara membuat Fanspage, dan blog sebagai media promosi. Kemajuan teknologi informasi sebagai media promosi cukup efisien untuk pengembangan usaha dan daya saing dengan melalui: media sosial, pilihan media sosial yang dapat digunakan adalah Fanspage, Instagram dan blog dengan jumlah pengguna lebih banyak dibandingkan media 
1001 Sosialisasi Diversifikasi dan Strategi Promosi dalam Meningkatkan Penjualan Produk Anyaman Purun Desa Perdamaian- T. Lyza Tahura Chairunnisa, Sarah Imelda, Ernita Rosmika

DOI: https://doi.org/10.31004/abdidas.v2i4.399

sosial lain. Keuntungan mempromosikan produk melalui media sosial adalah lebih efisien karena tidak berbayar dan memungkinkan penyebaran berita dari mulut ke mulut yang lebih cepat dan jangkauan media sosial juga sangat luas.

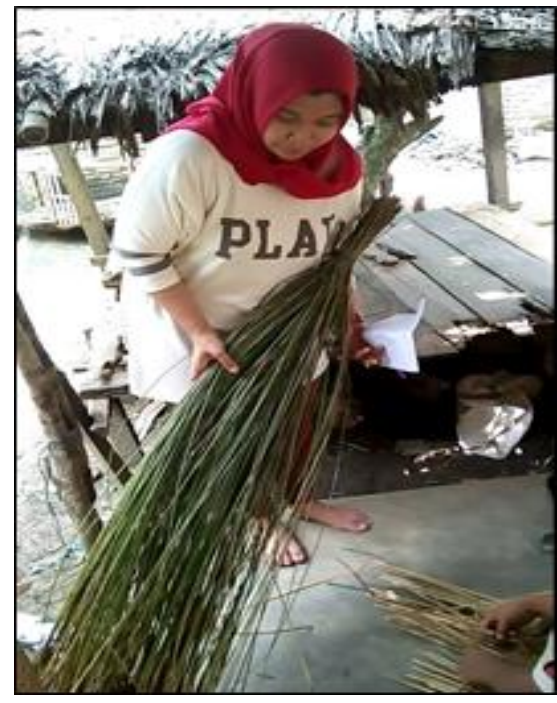

Gambar 3: Purun sebagai Bahan Baku Anyaman Tikar

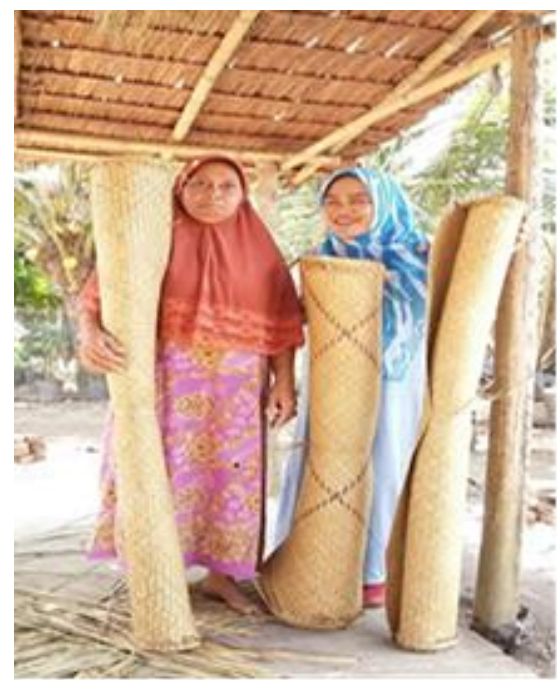

Gambar 4: Hasil Anyaman Tikar Purun

3. Evaluasi Pelaksanaan Kegiatan

Evaluasi diperlukan untuk menilai keberhasilan suatu kegiatan, khususnya pengabdian pada masyarakat ini. Produk anyaman tikar yang dibuat para mitra hanya berbentuk polos tanpa warna, dengan adanya penyuluhan mengenai diversifikasai dan strategi promosi membuat mitra mengetahui bagaimana membuat produk tikarnya menjadi lebih baik dan menarik dengan memberikan motif dan warna yang bagus serta promosi produk yang lebih maju seperti sistem online. Monitoring tetap akan dilakukan apakah mitra sudah melaksanakan semua hasil dari penyuluhan yang telah diberikan tim pengabdian pada masyarakat.

\section{SIMPULAN}

Mitra sangat antusias untuk mengikuti penyuluhan yang diberikan tim pengabdian masyarakat, dengan adanya penyuluhan ini mereka banyak mengerti bagaimana membuat suatu produk dengan nilai jual yang baik melalui diversifikasi produk dan strategi promosi yang benar. Untuk kedepannya kami mengharapkan olahan anyaman purun ini tidak monoton dalam satu bentuk saja, tetapi bisa diolah dalam bentuk tas, topi dan lainnya.

\section{UCAPAN TERIMA KASIH}

Tim mengucapkan terima kasih kepada pihak terkait dalam pelaksanaan kegiatan pengabdian masyarakat ini, Kepala Desa Dusun I Desa Perdamaian Kwala Begumit Kecamatan Binjai Kabupaten Langkat Sumatera Utara dan Mitra Pengrajin Anyaman Purun, sehingga kegiatan ini dapat terlaksana dengan baik dan lancar. 
1002 Sosialisasi Diversifikasi dan Strategi Promosi dalam Meningkatkan Penjualan Produk Anyaman Purun Desa Perdamaian- T. Lyza Tahura Chairunnisa, Sarah Imelda, Ernita Rosmika

DOI: https://doi.org/10.31004/abdidas.v2i4.399

\section{DAFTAR PUSTAKA}

Fandy, Tjiptono. (2008). Strategi Pemasaran. Andi Offset

Hendro. (2011). Dasar-Dasar Kewirausahaan, Panduan Bagi Mahasiswa Untuk Mengenal, Memahami dan Memasuki Dunia Bisnis. Erlangga

Kuncoro, Mudrajad. (2014). Otonomi Daerah, Menuju Era Pembangunan Daerah. Erlangga

Novriyanata, A., Abidin, Z., \& Rahmadi, A. (2018). Produktivitas Kerajinan Anyaman Purun Danau (Lepironia articulata Domin) Di Kelurahan Palam Kecamatan Cempaka Kota BanjarBaru Provinsi Kalimantan Selatan. 01(2), 160-170.

Nurhayati, Tri Kurnia. (2003). Kamus Lengkap Bahasa Indonesia. Eska Media.

Thamrin, S. A. M. (2012). Manfaat Purun Tikus. Jurnal Litbang Pertanian (. 31(1), 35-42.

Wijaya, Y. E., \& Karneli, O. (2017). Pengaruh diversifikasi produk dan harga terhadap kepuasan pelanggan (Studi Pada Pelanggan Kentucky Fried Chicken (KFC) Metropolitan City Pekanbaru). Jurnal Online Mahasiswa Fakultas Ilmu Sosial Dan Ilmu Politik Universitas Riau, 4(2), 1-15. 